\title{
Climate modulation of summer rainstorm activity in eastern China based on the Tibetan Plateau spring heating
}

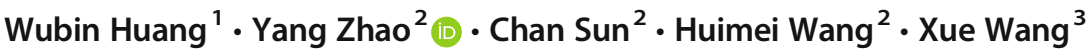 \\ Received: 3 April 2019 / Accepted: 8 January 2020 / Published online: 27 January 2020 \\ (C) The Author(s) 2020
}

\begin{abstract}
Rainstorm intensity and frequency in eastern China are closely associated with the Asian summer monsoon, one of the largest and most pronounced circulation systems on Earth. Changes in monsoon strength are linked to mechanical and thermal forcing by the Tibetan Plateau (TP), which, as an extensive elevated landmass, forms a vast heat source that protrudes into the free atmosphere. However, the impact of TP heating variability on rainstorm behavior in eastern China remains unclear. By analyzing 50 years of climate data, significant interannual variability was identified in the occurrence of rainstorms (precipitation amounts of $>50 \mathrm{~mm}$ ), with decreased trend in northern China and increased variability in southern China. Results show that these changes are closely related with the springtime TP heating, indicating that recent changes in rainstorm distributions in eastern China are consistent with interdecadal variability in TP thermal forcing.
\end{abstract}

Keywords Tibetan Plateau $\cdot$ Heat forcing $\cdot$ Rainstorm $\cdot$ Eastern China

\section{Introduction}

The Tibetan Plateau (TP) is often regarded as the roof of the world. Constituting approximately one sixth of Asia's total land area, the TP has an average elevation of $>4000 \mathrm{~m}$, nearly reaching the mid-troposphere. Duan et al. (2012) indicated that the TP could affect the weather and climate of the whole Asia. It is worth to explore whether the TP could affect Middle East regional in the future. The long periods of droughts, scarcity of water, and the huge variation in precipitation records are recorded in the regional scale in Iraq (Al-Ghadban et al. 2008), Iran (Al-Ghadban et al. 1999), and Kuwait (Al-Dousari 2005; Al-Dousari et al. 2007; Misak et al. 2007; Ahmed and Al-Dousari 2013; Al-Awadhi et al. 2014). In this study, we mainly focus on the TP heating in the spring to regulate the summer precipitation over the eastern China. Precipitation

Responsible Editor: Abdullah M. Al-Amri

Yang Zhao

qkylyy520@163.com

1 Lanzhou Central Meteorological Observatory, Lanzhou, China

2 State Key Laboratory of Severe Weather, Chinese Academy of Meteorological Sciences, Beijing, China

3 Huafeng Meteorological Media Group, Beijing, China over the TP, as in most of southern and eastern Asia, is dominated by the Asian summer monsoon, which has undergone an appreciable decrease in intensity in recent decades (Jiang and Wang 2005; Duan et al. 2011; Liu et al. 2012). The presence of a mid-troposphere "warm-wet island" over the TP is evident from positive differences in air temperature and humidity. On average, urban temperatures in this region are 1$3{ }^{\circ} \mathrm{C}$ higher than in surrounding rural environments (Voogt and Oke 2003), while summer air temperature over the TP is generally $4-6{ }^{\circ} \mathrm{C}$ warmer than at an equivalent altitude in the free atmosphere. Zhao et al. (2019a) emphasized that the eastern TP is a mainly heating source; it has important effect on the summer precipitation for the eastern slope of TP.

In the context of Northern Hemisphere summer precipitation, southern China stands out as an anomalously wet region in the otherwise dry subtropics due to the occurrence of the East Asian summer monsoon. As a key component of this seasonal wind reversal, the TP's mechanical and thermal forcing drive the vigorous transport of warm moist air that facilitates active convection (Zhao et al., 2016a, b, 2018, 2019b). The numerical experiments show that atmospheric heating induced by the rising TP temperature can reinforce the rainfall in East Asia (Wang et al. 2008). Hsu (2003) suggested that the Tibetan Plateau heating is accompanied with two wave-like circulation patterns. The wave-like feature in turn adjusts the East Asian summer rainfall. Duan et al. (2013) similarly 
indicated that the reduction heating over the TP results in crippling the East Asian summer monsoon circulation and leads to the precipitation location also rendering southerly.

Wang et al. (2014) used the numerical experiments and invested the sensible heat over the TP, which could regulate the interannual variability of East Asian summer monsoon in terms of wave activity and synoptic disturbances.

As demonstrated by previous studies, heating of the TP drives the Asian summer monsoon (Wu and Zhang 1998; $\mathrm{Xu}$ et al. 2010) and is linked to the intensity of the Hadley Circulation. An unanswered question, therefore, is how recent changes in monsoon intensity (Jiang and Wang 2005; Duan et al. 2011; Liu et al. 2012) might reflect variability in the thermal forcing of the TP. Moreover, previous studies were mainly focused on the precipitation rather than the rainstorm. The frequency of summer rainstorms in China and the broader East Asia region exhibits pronounced interannual and interdecadal variability. It is therefore important to understand how such behavior is connected to the springtime thermal effect of the TP.

In the present study of mean rainstorm frequency in China, we investigate the spatial distribution and interdecadal variability of rainstorms in monsoonal regions, with an emphasis on connections to summer monsoonal water vapor transport and the springtime TP thermal forcing. It is favorable for further understanding the thermal influence of TP and improving the summer precipitation forecast over the Eastern China.

\section{Data and method}

\section{Data}

For precipitation and surface temperature analyses, we employed data collected by a network of 753 observation stations over a period of 50 years (1961-2010). Data from these stations were quality controlled to ensure that there were no missing data, urban heat island effects, or location or instrument changes at a station, all of which would bias the trend analysis. They are archived from the China Meteorological Administration (http://www.cma.gov.cn/). The grade of rainstorms is defined by daily rainfall amounts of $>50 \mathrm{~mm}$, along with the duration of each event in days. The NCEP/ NCAR reanalysis data $\left(2.5^{\circ} \times 2.5^{\circ}\right)$ including wind, temperature, pressure, and specific humidity from 1961 to 2010 (https://www.esrl.noaa.gov/psd/data/gridded/) are used to calculate the apparent heat source $(Q 1)$ over the TP $(27$. $5^{\circ} \mathrm{N}-37.5^{\circ} \mathrm{N}, 80^{\circ} \mathrm{E}-105^{\circ} \mathrm{E}$ ), following the methodology (Yanai and Johnson 1993; Yanai and Tomita 1998), which incorporates radiative heating due to vertical transport of dry-static energy and latent heat release. The whole-column $Q 1$ is expressed in units of $\mathrm{W} \mathrm{m} \mathrm{m}^{-2}$. The NCEP/NCAR reanalysis data are also used to calculate the columnintegrated water vapor fluxes.

\section{Column-integrated water vapor fluxes}

Our study focuses on the relationship between rainstorm frequency and water vapor transport. We used the following equations with NCEP analysis data to compute the columnintegrated horizontal water vapor fluxes in the zonal $(q u)$ and meridional $(q v)$ directions:

$q u(x, y, t)=-\frac{1}{g} \int_{p_{s}}^{p_{T}} q u(x, y, p, t) d P$

$q v(x, y, t)=-\frac{1}{g} \int_{p_{s}}^{p_{T}} q v(x, y, p, t) d P$

where $x$ is the zonal field, $y$ expresses the longitudinal field, $p$ means the vertical level, and $t$ represents the time. $g$ is the accelerated speed due to gravity, $q$ is defined as the specific humidity, $u$ and $v$ are the zonal and meridional wind. $P s$ is the pressure at the sea surface level, and $P_{T}$ is the pressure at the top atmospheric level.

\section{Correlation vector}

To elucidate the relationship between rainstorms in eastern China and column-integrated water vapor transport, particularly the role of moisture transport during years of anomalous rainstorm activity, we computed the correlation vector to track water vapor sources and transport pathways, as follows:

$R(x, y)=R_{u}(x, y)+R_{v}(x, y)$

where $R_{u}(x, y)$ and $R_{v}(x, y)$ represent the correlation coefficients between the frequency of rainstorms or rainfall and column-integrated zonal/meridional water vapor fluxes $q u$ and $q v$, respectively (Zhao et al. 2016b).

\section{The apparent heat source (Q1)}

To calculate the spring heat over the TP, the formula of apparent heat source Q1 is defined as (Nitta 1983; Duan et al. 2013)

$Q_{1}=C_{p}\left(\frac{\partial T}{\partial t}+\vec{V} \cdot \nabla T+\omega\left(\frac{P}{P_{0}}\right)^{k} \frac{\partial \theta}{\partial P}\right)$

where $T$ is the temperature, $\omega$ is the vertical speed in Pcoordinate, and $C_{p}$ is the specific heat capacity of air at constant pressure. $V$ denotes the horizontal speed. $\theta$ means the potential temperature. $P$ is the atmosphere pressure and $p_{0}$ represents the pressure at level $1000 \mathrm{hPa}$. 


\section{Changing patterns of summer rainstorm activity over eastern China}

\section{Distribution patterns}

Disaster analysis data indicates that most of rainstorm hazards are located in the subtropical monsoon region. Over the course of the 1954 Meiyu period, for example, persistent heavy rainfall resulted in the catastrophic flooding of the Yangtze River, while heavy rain in the middle and lower reaches of both the Yangtze River and the Huaihe River valleys led to flooding again in 1991. Extremely persistent rainstorm activity in 1998 delivered $>600 \mathrm{~mm}$ to most parts of the Yangtze River basin (Sun et al. 2018).

Figure 1 shows the geographic distribution of the number of annual days (1961-2010) with summer rainstorms of $>$ $50 \mathrm{~mm}$ (Fig. 1). Figure 1 shows that the number of days with rainstorms delivering $>50 \mathrm{~mm}$ is largest in southern China (south of $35^{\circ} \mathrm{N}$ latitude and east of $110^{\circ} \mathrm{E}$ longitude).

\section{Long-term trends and inter-annual variations}

Extreme precipitation events have increased in frequency in the Yangtze River basin, especially in the middle and lower Yangtze reaches ( $\mathrm{Su}$ et al. 2006). The temporal and spatial variation analysis (1961-2010) of days with precipitation $>$ $50 \mathrm{~mm}$ in southern China region (south of $35^{\circ} \mathrm{N}$ and east of $110^{\circ} \mathrm{E}$ ) are shown in Figs. 2 and 3, respectively. Figure 3 shows an increasing trend in these events in the southern China region, in terms of both number of days (black solid line) and number of stations (blue solid line) have passed the 90\% confidence test. Similarly, a positive trend is observed in the middle and lower reaches in the Yangtze River Basin, as floods have increased in recent years (Jiang et al. 2007).
From the perspective of temporal and spatial changes in high-frequency rainfall, our analysis supports the increased occurrence of heavy rainfall events in the Yangtze River Basin and suggests that throughout southern China, the most significant transition occurred in 1993 and 2003 (Fig. 3, blue solid line). We also found a significant increase in the number of days with precipitation in excess of 100 and $200 \mathrm{~mm}$ (not shown), with the most prominent increases occurring during the same period as the $>50 \mathrm{~mm}$ days (Fig. 3). Therefore, we can conclude that rainstorms in southern China have not only increased in number and intensity, but also covered a greater geographic area.

\section{Anomalies and long-term trends in springtime heating of the Tibetan Plateau}

\section{Connections to rainstorm activity in eastern China}

Meiyu rainfall in the Yangtze River and Yellow River basins results from summertime wind dynamics and water vapor flux and is linked to monsoonal airflow induced by heating of the TP. Water vapor flux from the low-latitude oceans climbs or bypasses the TP to the east and moves toward the eastern part of China, especially southeastern China, affecting both the distribution and timing of rainstorm events. Considering that China rainstorms exhibit an increasing trend, we calculated correlation vectors between summer eastern China (east of $105^{\circ} \mathrm{E}$ ) rainstorms $>50 \mathrm{~mm}$ and the total-column water vapor flux. It is found that the water vapor is transported from the South China Sea and Bay of Bengal in summer (Fig. 4). Therefore, the structure of continuous large-scale water vapor transport remains one of the key factors with respect to the summer monsoon impact on China rainstorms.
Fig. 1 Distribution of the number of days annually with summer rainstorms of greater than $50 \mathrm{~mm}$ daily precipitation, averaged over the period 1961-2010. Different size and color dots mean rainstorm frequency distribution in summer

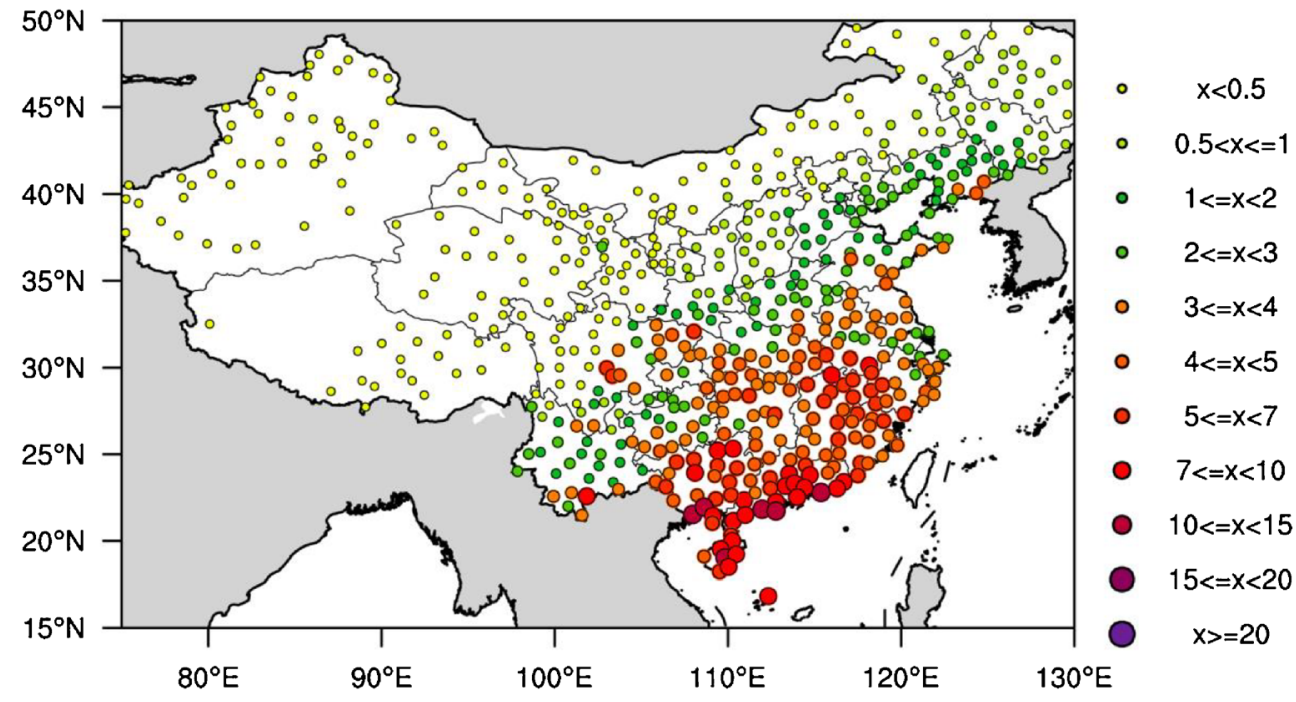


Fig. 2 Distribution of trends (days per decade) in the number of summer rainstorm days with daily precipitation $>50 \mathrm{~mm}$ for the period 1961-2010. Note: the color shading is the height of terrain. The purple dash line is the southern China area (south of $35^{\circ} \mathrm{N}$ latitude and east of $110^{\circ} \mathrm{E}$ longitude)

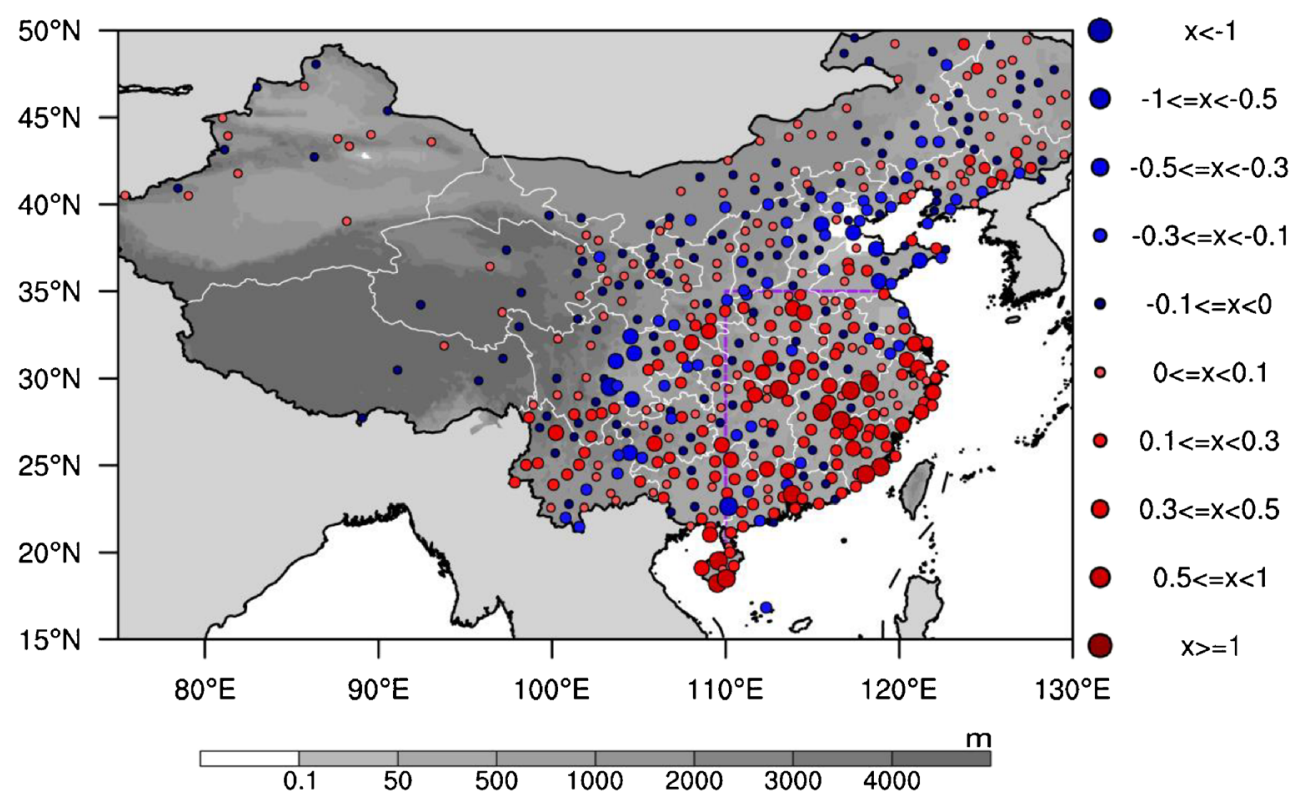

The TP characterized by a hollow "heat island" phenomenon is significantly correlated with the hemisphericscale zonal hydrological cycle. Specifically, midtropospheric convection over the plateau serves to draw in moist air from the low-latitude ocean, setting up a direct link between the intensity of TP heating and the water vapor activity of the Western Pacific. Springtime heating of the TP $(Q 1)$ and its related water vapor distribution flow vector are prominent features of the summer monsoon associated with Meiyu rainfall. And the diminished heat island effect on the TP serves to reduce the land-sea thermal contrast, resulting in a weakened monsoon and a "south floods north drought" pattern. Previous studies have shown that strong heating of the TP changes the structure of water vapor transport to East Asia, as well as the spatial and temporal variation of summer monsoon precipitation (Xu et al. 2013).

\section{Change in apparent heat source}

To investigate whether the spatio-temporal distribution of summer rainstorm frequency in eastern China is affected by thermal conditions over the TP, we calculated the related coefficient field between TP spring whole layer heat (Q1) (March, April, and May) and the number of days in which China summer (June, July, and August) precipitation was $>50 \mathrm{~mm}$ (Fig. 5). Figure 5 shows that TP spring whole layer heat $(Q 1)$ and rainstorm days in southeast China are negatively correlated. In contrast, Fig. 5 shows positive correlations over northern and northeastern
Fig. 3 Interannual variations in the number of days (black line) and stations (blue line) recording summer rainstorms with daily precipitation $>50 \mathrm{~mm}$ between 1961 and 2010. Both datasets have been compiled and averaged over the southern China region (south of $35^{\circ} \mathrm{N}$ and east of $110^{\circ} \mathrm{E}$, the purple dash line in Fig. 2)

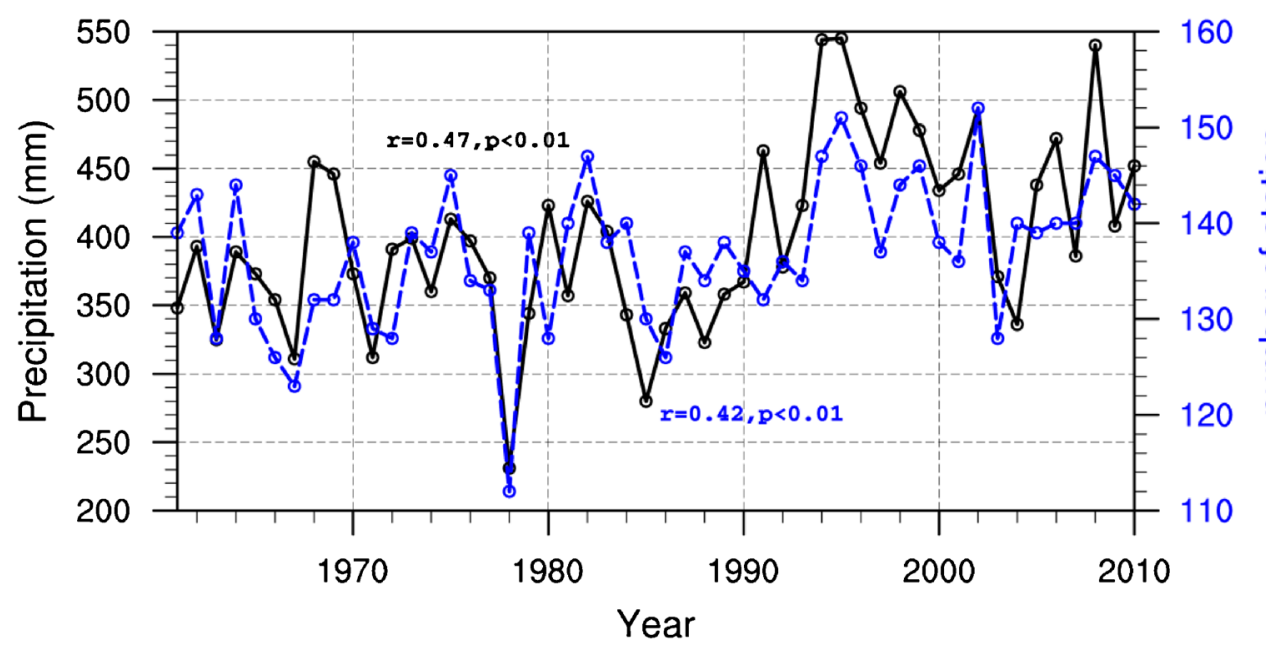

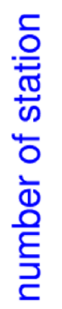


Fig. 4 Correlation vectors between summer rainstorms > $50 \mathrm{~mm}$ in Eastern China (east of $\left.105^{\circ} \mathrm{E}\right)$ and the total-column water vapor flux. Red/blue shading indicates areas with positive/negative correlation significance confidence greater than $90 \%$

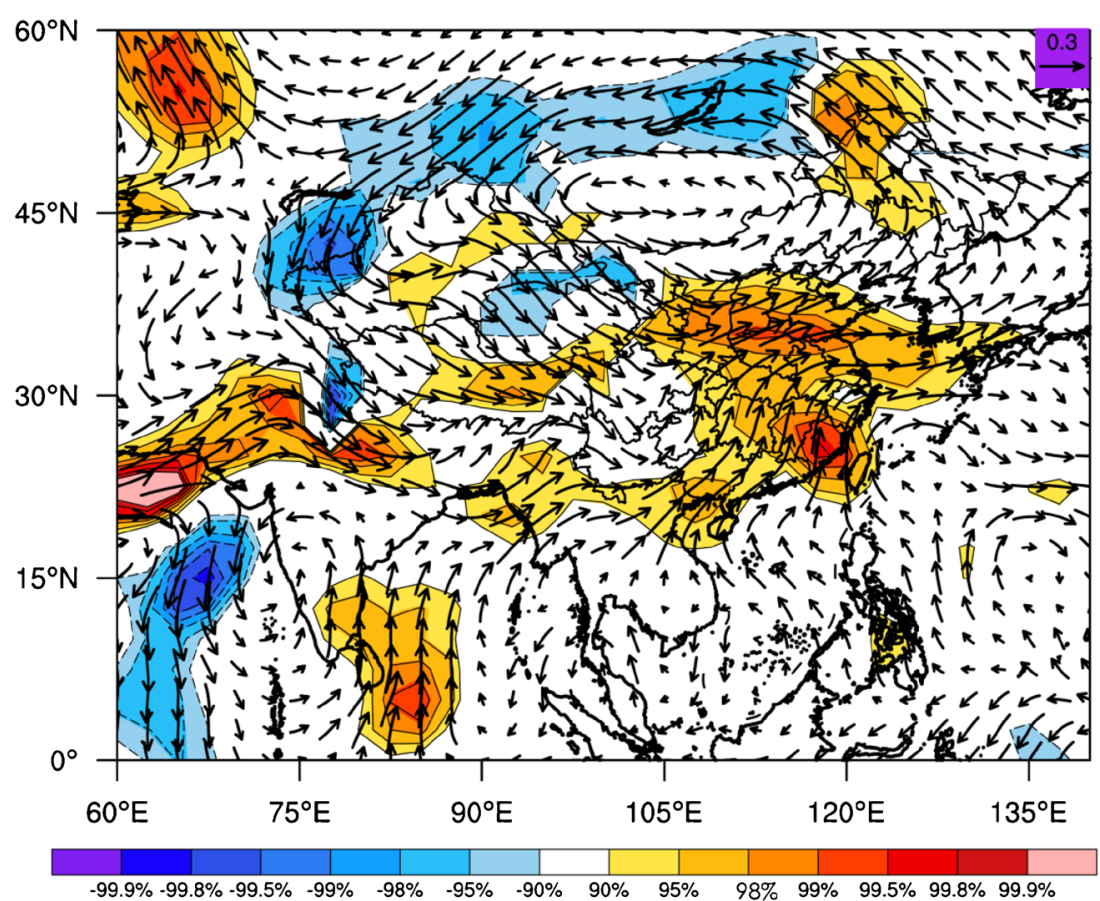

China. These results suggest that springtime heating of the TP $(Q 1)$ affects the north-south summer rainstorm distribution via modulating the summertime monsoonal water vapor transport. In other words, spring heating over the TP is associated with high (low) rainstorm frequency in the northern (southern) China, due to the change in water vapor transport pathway.

Figure 6 a depicts interannual variations in springtime heating of the TP for the period 1961-2010, which can be divided into three distinct sub-periods: (p1) 1961-1980, (p2) 1981-2003, and (p3) 2003-2010. Figure 6 shows an increasing trend in sub-period ( 1 1), a decreasing trend in sub-period (p2), and a slightly rebound in sub-period (p3). The springtime heating of the TP corresponds to the interdecadal frequency variability of $>50-\mathrm{mm}$ rainstorm anomaly. It showed that the stronger for the springtime heat over the TP, the more northward movement of the rainstorm anomaly greater value in summer. During the sub-period ( $\mathrm{p} 1)$, the enhanced springtime heating of the TP corresponds to Fig. 6b (A, B), which shows decreased
Fig. 5 Distributions of correlation coefficients between the springtime apparent heat source (Q1) over the TP and the number of days with summer rainstorms (daily precipitation $>50 \mathrm{~mm}$ ) over China for the period 19612010 (contour). The solid and dashed lines are the correlative confidence more than $90 \%$

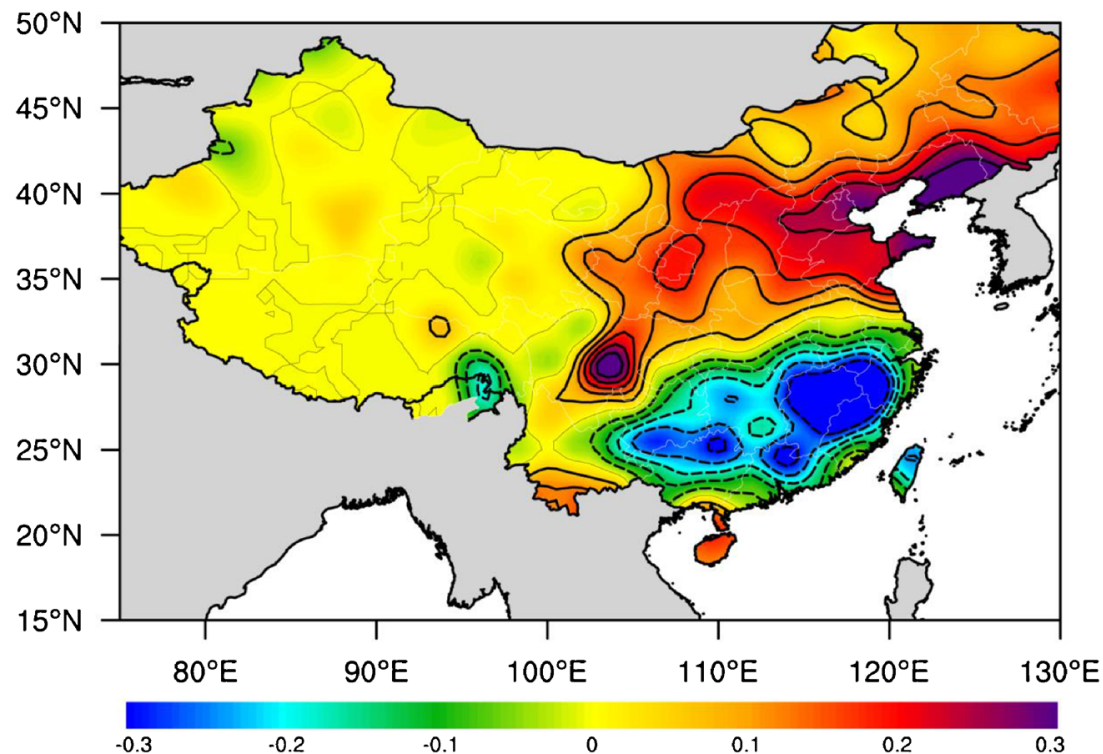


Fig. 6 Interannual variability (blue line) and trends in apparent springtime heating over the TP $\left(27.5^{\circ} \mathrm{N}-37.5^{\circ} \mathrm{N}, 80^{\circ} \mathrm{E}-105^{\circ} \mathrm{E}\right)$ (a), alongside interdecadal patterns of days with summer rainstorms anomaly (daily precipitation $>50 \mathrm{~mm}$ ) over eastern China between 1961 and 2010 (b [A-E])

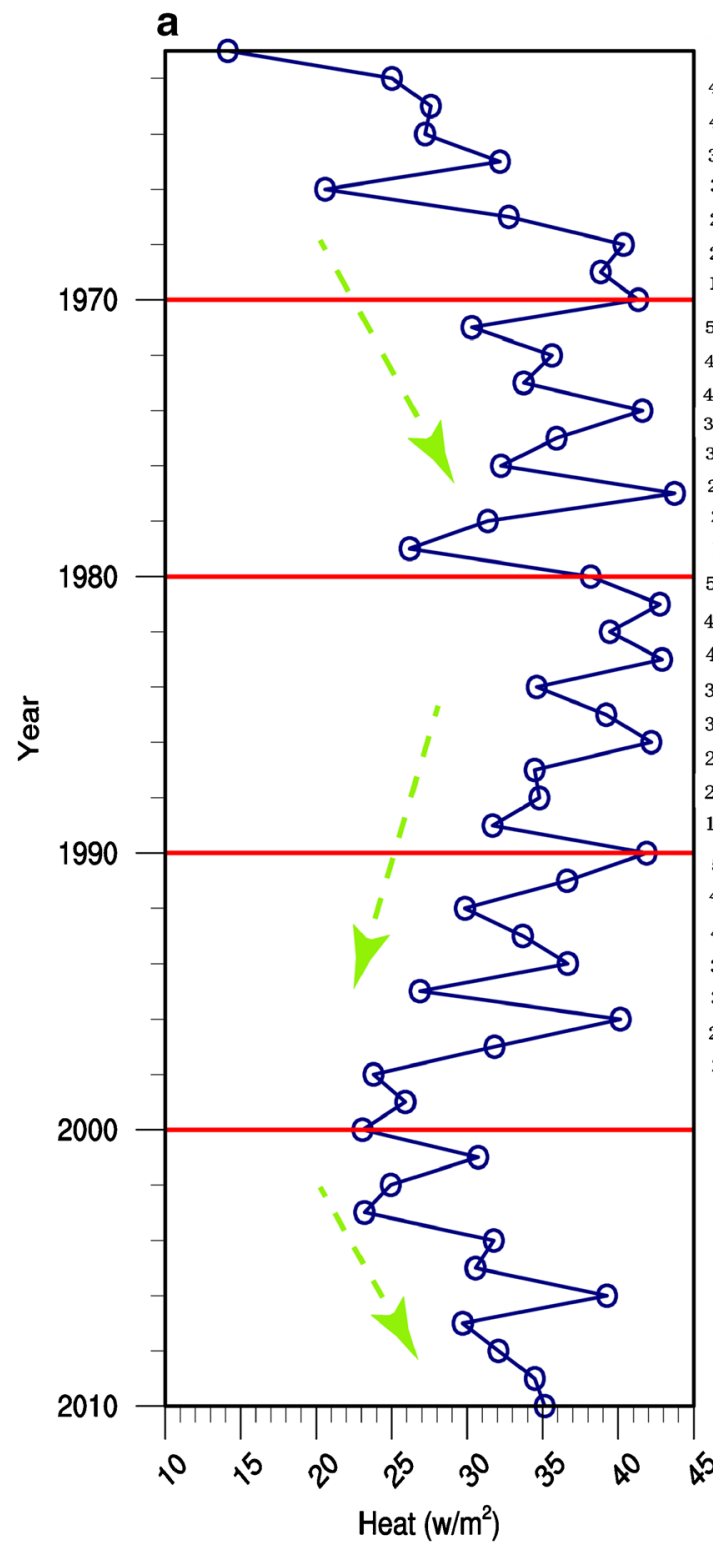

b

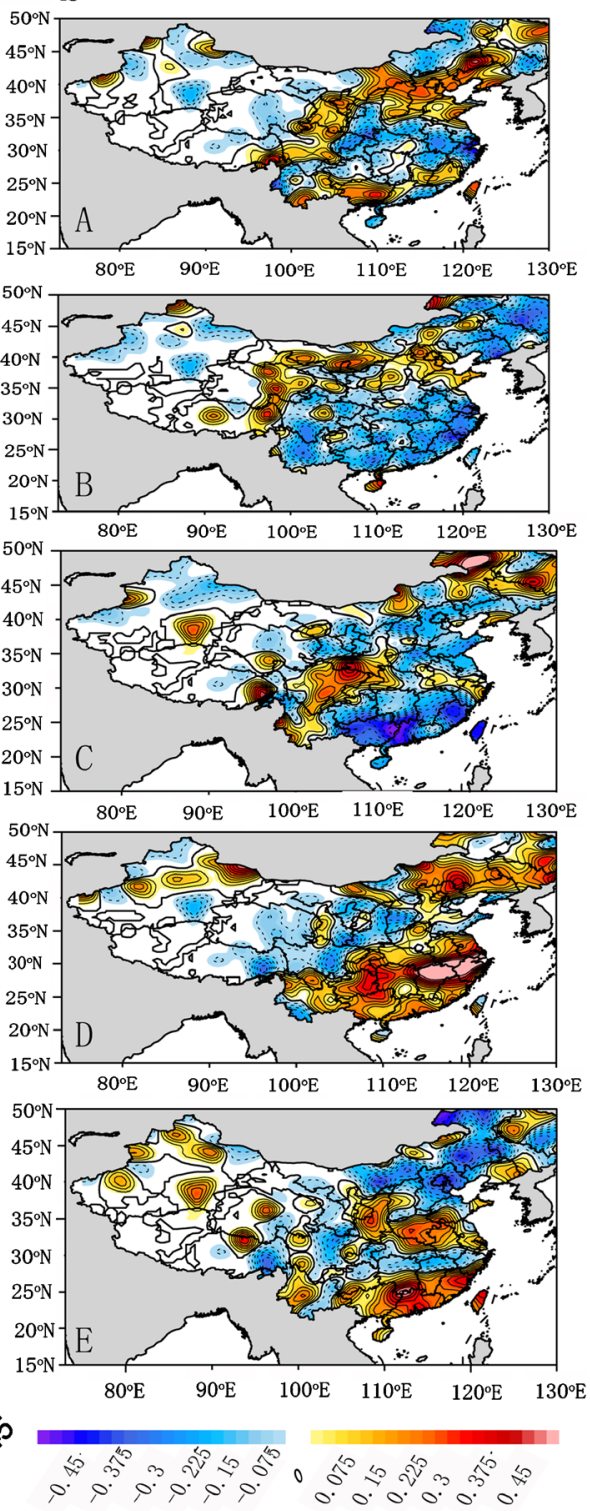

rainstorm frequency over southern China and increased frequency over northern China. In sub-period (p2), decreasing TP heating is related to increased rainstorm frequency over southern China. These results indicate a "South flood and North dry" dipole pattern during times of a weaker summer monsoon, specifically 1981-2003 (Fig. 6b (C, D)). During the sub-period (p3), the slightly increasing springtime heating of the TP corresponds to Fig. $6 \mathrm{~b}(\mathrm{E})$, which shows decreased rainstorm frequency over mid-eastern China.

Overall, Fig. 6a, b shows that spring heat over the TP modulates the interdecadal spatio-temporal distribution of summer rainstorms in China. It is noteworthy that this modulation is not limited to the number $>50 \mathrm{~mm}$ rainstorms; results for $>$ 100-mm events (not shown) shows a similar north-south variability pattern to that seen in Fig. 6.

\section{Conclusions}

In this study, we investigate the spatial distribution and interdecadal variability of rainstorms in monsoonal regions. Analysis data and gauge data are used to calculate the spring heating over the Tibetan Plateau as well as the summer rainstorm frequency over the eastern China. We try to analyze the correlative relationship between the spring heating over the $\mathrm{TP}$ and summer rainstorm over the eastern China. The results 
are helpful to improve the summer extreme precipitation forecast ability based on the spring heating of Tibetan Plateau.

As a major climatic feature in eastern China, rainstorm events are closely linked to the Asian summer monsoon. Our analysis of climate data shows that rainstorm intensity and frequency have varied significantly over the 1961-2010 period. The Asian summer monsoon is one of the largest and most pronounced circulation systems influenced by mechanical and thermal forcing of the TP, which forms a vast heat source protruding into the free atmosphere. Based on the moisture correlative pathways analysis and calculated the atmospheric apparent heat source, we examined the impact of apparent spring heating on summer rainstorm frequency in eastern China and identified significant correlations between the spring heating of TP and Asian summer monsoon rainstorm frequency. Specifically, anomalous rainstorm patterns are traceable back to the response of moisture transport to the anomalous heating over the TP, which is consistent with the established understanding of TP-monsoon dynamics. Further analysis of long-term trends in apparent heating suggests that changes over the TP could adjust the distribution of rainstorm. The correlative relationship between the heating and rainstorm frequency shows positive correlation over the North China and negative correlation over the South China. That means, the stronger spring heating of TP, the farther north of the monsoon precipitation. For instance, the decrease in apparent TP heating in recent decades might be responsible for the coincident weakening of the East Asian summer monsoon. In addition, a finding of our study, which has not been discussed in the present paper, it shows a distinct reversal in this decreasing trend after 2003. A longer record of observational data is required to verify this trend. The connecting between the heating over the TP and rainstorm of Eastern China helps up deeply understand the rainstorm mechanism of Eastern China and enhance the rainstorm predictive ability.

In this study, we just focus on the TP heating affecting the rainstorm over the Eastern China. However, the dynamic and thermal of TP could have effect on the whole Asia (Duan and Wu 2005; Wu et al. 2007). Few knows how TP affects the Central Asia area, as described that the long periods of droughts, scarcity of water, and the huge variation in precipitation records are recorded in the regional scale in Iraq (AlGhadban et al. 2008), Iran (Al-Ghadban et al. 1999), and Kuwait (Al-Dousari 2005; Al-Dousari et al. 2007; Misak et al. 2007; Ahmed and Al-Dousari 2013; Al-Awadhi et al. 2014). In the further study, it is worth to explore how the TP affects Middle East regional scale.

Acknowledgements We sincerely thank two anonymous reviewers whose comments greatly improved the manuscript. We acknowledge the National Meteorological Information Center of the China Meteorological Administration for providing the observational daily precipitation dataset (http://data.cma.cn/), and NCEP/NCAR reanalysis data $\left(2.5^{\circ} \times 2.5^{\circ}\right)(\mathrm{https}: / /$ www.esrl.noaa.gov/psd/data/gridded/).
Funding information Foundation item: this research was supported by several sources, including National Key R\&D Program of China (2018YFC1507805); Gansu Meteorology Administration Foundation (Ms2020-06; GSQXCXTD-2017-01); China Meteorology Administration Foundation (CMAYBY2020-134; 2015BAC03B06; YBGJXM(2019)01-06); The Jiangsu Postgraduate Research and Innovation Program projects (KYCX17_0869).

Open Access This article is licensed under a Creative Commons Attribution 4.0 International License, which permits use, sharing, adaptation, distribution and reproduction in any medium or format, as long as you give appropriate credit to the original author(s) and the source, provide a link to the Creative Commons licence, and indicate if changes were made. The images or other third party material in this article are included in the article's Creative Commons licence, unless indicated otherwise in a credit line to the material. If material is not included in the article's Creative Commons licence and your intended use is not permitted by statutory regulation or exceeds the permitted use, you will need to obtain permission directly from the copyright holder. To view a copy of this licence, visit http://creativecommons.org/licenses/by/4.0/.

\section{References}

Al-Dousari AM (2005) Causes and indicators of land degradation in the North-Western part of Kuwait. Arab Gulf J Scientific Res 23(2):6979

Al-Ghadban AN, Uddin S, Beg MU, Al-Dousari AM, Gevao B, AlYamani $F$ (2008) Ecological consequences of river manipulations and drainage of Mesopotamian marshes on the Arabian gulf ecosystem: investigations on changes in sedimentology and environmental quality, with special reference to Kuwait Bay. KISR 9362:1-141

Al-Dousari AM, Misak RF, Al Gamily H, Neelamani N (2007). Integrated system for flood management in Shuaiba area and its vicinities. KISR EC055C final report, KISR, 8910

Ahmed M, Al-Dousari AM (2013) Geomorphological characteristics of the um-Rimam depression in northern Kuwait. Kuwait J Sci 40(1): $165-178$

Al-Awadhi JM, Al-Dousari AM, Khalaf FI (2014) Influence of land degradation on the local rate of dust fallout in Kuwait. Atmospher Climate Sci 4(03):437-446. https://doi.org/10.4236/acs.2014.43042

Al-Ghadban AN, Saeed T, Al-Dousari AM, Al-Shemmari H, Al-Mutairi M (1999) Preliminary assessment of the impact of draining of Iraqi marshes on Kuwait's northern marine environment. Part I Physic manipul Water sci Technol 40(7):75-87

Duan AM, Wu GX (2005) Role of the Tibetan plateau thermal forcing in the summer climate patterns over subtropical Asia. Clim Dyn 24: 793. https://doi.org/10.1007/s00382-004-0488-8

Duan AM, Li F, Wang M (2011) Persistent weakening trend in the spring sensible heat source over the Tibetan plateau and its impact on the Asian summer monsoon. J Clim 24:5671-5682

Duan AM, Wang M, Lei Y (2013) Trends in summer rainfall over China associated with the Tibetan plateau sensible heat source during 1980-2008. J Clim 26(1):261-275

Duan AM, Wu GX, Liu YM (2012) Weather and climate effects of the Tibetan plateau. Adv Atmos Sci 29(5):978-992

Hsu HH (2003) Relationship between the Tibetan Plateau heating and East Asian summer monsoon rainfall. Geophys Res Lett 30(20): 2066

Jiang D, Wang H (2005) Natural interdecadal weakening of East Asia summer monsoon in the late 20th century. Sci Bull 50:1923-1929 
Jiang T, Su B, Hartmann H (2007) Temporal and spatial trends of precipitation and river flow in the Yangtze River basin, 1961-2000. Geomorphology 85:143-154

Liu YM, Wu GX, Hong JL (2012) Revisiting Asian monsoon formation and change associated with Tibetan plateau forcing: II. Change. Clim Dyn 39:1183-1195

Misak R, Al-Dousari A, Al-Hagraf S (2007) Combating land degradation using eco-friendly materials. In international conference on desertification control in the arid region, pp 12-15

Nitta T (1983) Observational study of heat source over the eastern Tibetan plateau during summer monsoon. J Meteor Res Japan 61(4):590 605

Sun X, Jiang G, Ren X (2018) Role of intraseasonal oscillation in the persistent extreme precipitation over the Yangtze River basin during June 1998. J Geophys Res 121(18):10453-10469

Su BD, Jiang T, Jin BW (2006) Recent trends in observed temperature and precipitation extremes in the Yangtze River basin, China. Theor App Climatol 83:139-151

Voogt JA, Oke TR (2003) Thermal remote sensing of urban climates. Remote Sens Environ 86:370-384

Wang B, Bao Q, Hoskings B (2008) Tibetan plateau warming and precipitation changes in East Asia. Geophys Res Lett 35(14):63-72

Wang ZQ, Duan AM, Wu GX (2014) Time-lagged impact of spring sensible heat over the Tibetan plateau on the summer rainfall anomaly in East China: case studies using the WRF model. Clim Dyn 42: 2885. https://doi.org/10.1007/s00382-013-1800-2

Wu GX, Zhang YS (1998) Tibetan plateau forcing and the Asian monsoon onset over South Asia and South China Sea. Mon Weather Rev 126:913-927

Wu GX, Liu YM, Zhang Q (2007) The influence of mechanical and thermal forcing by the Tibetan plateau on Asian climate. J Hydrometeorol 8(4):770-789
Xu XD, Lu CG, Shi XH, Ding YH (2010) Large-scale topography of China: a factor for the seasonal progression of the Meiyu rainband. $\mathrm{J}$ Geophys Res 115:D02110

$\mathrm{Xu}$ XD, Lu CG, Ding YH (2013) What is the relationship between China summer precipitation and the change of apparent heat source over the Tibetan plateau. Atmos Sci Lett 14:227-234

Yanai M, Johnso RH (1993) Impacts of cumulus convection on thermodynamic fields. Amer Meteor Soc 24:39-62

Yanai M, Tomita T (1998) Seasonal and interannual variability of atmospheric heat sources and moisture sinks as determined from NCEPNCAR reanalysis. J Clim 11:463-482

Zhao Y, Xu XD, Chen B (2016a) The upstream "strong signals" of the water vapor transport over the Tibetan plateau during a heavy rainfall event in the Yangtze River basin. Adv Atmos Sci 33(12):13431350

Zhao Y, Xu XD, Zhao TL (2016b) Extreme precipitation events in East China and associated moisture transport pathways. Sci China (Ser D) 59(9):1-19

Zhao Y, Xu XD, Ruan Z (2018) Precursory strong-signal characteristics of the convective clouds of the central Tibetan plateau detected by radar echoes with respect to the evolutionary processes of an eastward-moving heavy rainstorm belt in the Yangtze River basin. Meteorog Atmos Phys 131:697-712. https://doi.org/10.1007/ s00703-018-0597-2

Zhao Y, Xu XD, Liao LF (2019a) The severity of drought and precipitation prediction in the eastern fringe of the Tibetan plateau. Theor Appl Climatol 137:141-152. https://doi.org/10.1007/s00704-0182564-8

Zhao Y, Xu XD, Liu LP (2019b) Effects of convection over the Tibetan plateau on rainstorms downstream of the Yangtze River basin. Atmos Res 219:24-35 